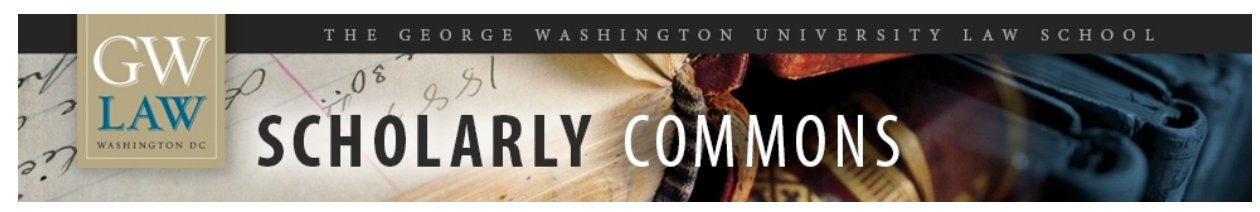

\title{
Indefinite-Delivery/Indefinite-Quantity Contracts: Time to Correlate Practice and Policy?
}

\author{
Steven L. Schooner \\ George Washington University Law School, sschooner@law.gwu.edu
}

Follow this and additional works at: https://scholarship.law.gwu.edu/faculty_publications

Part of the Law Commons

\section{Recommended Citation}

Schooner, Steven L., Indefinite-Delivery/Indefinite-Quantity Contracts: Time to Correlate Practice and Policy? (September 2018). Steven L. Schooner, Indefinite-Delivery/Indefinite-Quantity Contracts: Time to Correlate Practice and Policy?, 32 Nash \& Cibinic Rep. 944 (2018).; GWU Law School Public Law Research Paper No. 2018-38; GWU Legal Studies Research Paper No. 2018-38. Available at SSRN: https://ssrn.com/abstract=3241013

This Article is brought to you for free and open access by the Faculty Scholarship at Scholarly Commons. It has been accepted for inclusion in GW Law Faculty Publications \& Other Works by an authorized administrator of Scholarly Commons. For more information, please contact spagel@law.gwu.edu. 


\section{THE \\ NASH \& CIBINIC \\ REPORT $\begin{aligned} & \text { government contract analysis and advice monthly from } \\ & \text { professors ralph c. nash and john cibinic }\end{aligned}$}

Author: Ralph C. Nash, Professor Emeritus of Law, The George Washington University

Contributing Authors: Vernon J. Edwards and Steven L. Schooner

\section{ๆ 44 INDEFINITE-DELIVERY/INDEFINITE-QUANTITY CONTRACTS: Time To Correlate Practice And Policy?}

Steven L. Schooner

Don't look now, but a recent Government Accountability Office report suggests that, consistent with their popularity, indefinite-delivery/indefinite-quantity contracts are playing an increasingly dominant role in federal procurement. Defense Contracting: Use by the Department of Defense of Indefinite-Delivery Contracts from Fiscal Years 2015 through 2017, GAO18-412R (May 10, 2018). See 60 GC II 168.

This won't surprise N\&CR readers, many of whom have experienced this trend, on a transaction-by-transaction basis. In June 2017, we described the GAO's prior effort to chronicle the increasing popularity and growth of IDIQ contracts in a more fulsome report, acknowledging that IDIQs "have become the procurement instrument of choice in a wide variety of situations." See Indefinite Delivery/Indefinite Quantity Contracts: A Popular Vehicle, 31 NCRNL II 37, where we discussed Federal Contracts: Agencies Widely Used Indefinite Contracts To Provide Flexibility To Meet Mission Needs, GAO-17-329 (Apr. 13, 2017). Our sense is that the numbers, and the upward trend, merit further examination.

We continue to believe that "[w]ith the heavy workload imposed on most contracting offices and the continual pressure to minimize the number of contracting personnel, the IDIQ contract is here to stay," 31 NCRNL II 37. And we were not surprised that the GAO described, as "stable," the proportion of spending by federal agencies on IDIQ contracts—from fiscal years 2011 through 2015-at approximately a third of total Government contract obligations.

\section{A Modest Increase, A Significant Percentage}

In 31 NCRNL II 37, we didn't dwell on that one-third figure, even though closer examination of the GAO's data showed a small decrease in IDIQ spending from 2011 to 2012, and then again from 2012 to 2013, before stabilizing from 2013 through 2015. At the time, the figure seemed reasonable to the extent that the Department of Defense's reliance on IDIQs tracked the Government-wide trend, with the GAO highlighting a decrease in DOD IDIQ spending from more than $\$ 125$ billion in 2011, to under $\$ 100$ billion for 2013 through 2015.

Less than a year later, that stability appears more like a temporary plateau. In the May 2018 report (again, limited to the DOD), the GAO explained that orders under indefinite-delivery contracts comprised roughly 40\% of DOD obligations in FYs 2015 through 2017. During that brief three-year window, the DOD went from $\$ 89.1$ billion in IDIQ spending in 2015 to more than $\$ 105.6$ billion in 2017 - that's an increase of more than $18 \%$, which seems significant.

\section{Regulations Do Not Reflect The New Normal}

One of the most striking aspects of this phenomenon is how, over time, while procurement practices have evolved, the regulatory rubric has failed to keep up. In other words, we find it remarkable how inadequately the Federal Acquisition Regulation describes the process through which $40 \%$ of the DOD's acquisition spending flows. 
As most N\&CR readers know, it wasn't always this way. See Contract Types: There Are More Things in Heaven and Earth, Judge, Than Are Dreamt of in the FAR, 32 NCRNL II 3; What Rough Beast?: Basic Ordering Agreements-Innovation and Confusion, 25 N\&CR II 62; BPAs vs. IDIQs: An Interesting Choice, 24 N\&CR II 26; and Postscript II: Blanket Purchase Agreements, 23 N\&CR II 64. Today, a casual FAR reader (if there is such a person) would be hard pressed to intuit the current role of IDIQs from the existing regulatory structure. Granted, the FAR wasn't promulgated for casual readers. Still, the FAR seems rather dramatically divorced from current IDIQ practice. For example, it seems strange that, in effect, the seemingly impenetrable and oft-challenged guidance in FAR 16.505 controls such a significant slice of the procurement pie. See, e.g., Kingdomware Technologies, Inc. v. U.S., 136 S. Ct. 1969 (2016), 58 GC II 227 (discussing, inter alia, "the distinction between FSS orders and contracts"). This is by no means a unique problem within the FAR. As Vern noted in Get Rid of the Clutter: "Streamline" the FAR, 31 N\&CR II 27, over three decades, "the FAR has grown. As it grows it becomes more unwieldy, and its content seems to become murkier." But, given the GAO's findings, the lack of a regulatory big picture, roadmap, or structure with regard to IDIQs seems like a big deal.

Let's start at the beginning. FAR Part 2 suggests that the indefinite-delivery contract, "the procurement instrument of choice" (as the GAO notes above), doesn't even merit a standalone definition. (The only mentions of IDIQs in FAR Part 2 are found in the context of interagency acquisition (under the definition of "direct acquisition") and "multiple-award contract[s]" (which, as discussed below, represent the minority of IDIQs, despite the FAR's stated preference).) Conversely, "delivery order" and "task order" are defined, and various flavors of "orders" fall under the definition of "contract" and receive treatment in the definitions of "assisted acquisition," "Governmentwide acquisition contract (GWAC)," "multi-agency contract (MAC)," and "multipleaward contract."

Similarly, the FAR buries - at FAR 8.004(a) — under the umbrella of "other sources" or places agencies could "consider" if "mandatory sources" fail to satisfy the agency's requirements—common IDIQ vehicles such as "Federal Supply Schedules, Governmentwide acquisition contracts, multi-agency contracts, and any other procurement instruments intended for use by multiple agencies, including blanket purchase agreements (BPAs) under Federal Supply Schedule contracts."

Viewed from another perspective, FAR Subpart 16.1, "Selecting Contract Types," makes no mention of IDIQs and, instead, explains in FAR 16.101(b) that "contract types are grouped into two broad categories: fixed-price contracts (see [FAR] subpart 16.2) and cost-reimbursement contracts (see [FAR] subpart 16.3)." Similarly, FAR Part 16 plows through fixed-price contracts (FAR Subpart 16.2), cost-reimbursement contracts (FAR Subpart 16.3), and even incentive contracts (FAR Subpart 16.4), before turning to indefinite-delivery contracts (FAR Subpart 16.5). (As an aside, FAR Subpart 16.5 offers a basic introduction to requirements contracts (FAR 16.503), but doesn't pair them with output contracts as the does the Uniform Commercial CodeUCC 2-306, "Output, Requirements and Exclusive Dealings.") Granted, FAR Subpart 16.5 provides more guidance than RESTATEMENT (SECOND) OF ConTRACTS, which barely acknowledges IDIQ contracts, primarily addressing the concepts in terms of meeting the consideration requirement. See, e.g., the illustrations following $\S 77$, "Illusory and Alternative Promises" and in offers proposing a number or a series of contracts $(\S 31)$. Nor does one find particularly helpful guidance in Defense FAR Supplement Subpart 216.5, "Indefinite-Delivery Contracts," or PGI 216.1 (which merely references a DOD memorandum on incentive contracts and some guidance on research and development contracts) or PGI 216.5 (which speaks only to ordering with regard to exceptions to the fair opportunity process).

Despite ubiquitous use, the FAR suggests that, with regard to commercial purchasing, IDIQs are the exception, to the extent they are introduced in FAR 12.207(b) and (c), which focuses disproportionately on the requirements for Contracting Officers to execute a determination and findings (D\&F). (Of course, FAR 12.207(c)(1) cross-references FAR Subpart 16.5, which brings us full circle.)

In terms of simplified procedures, FAR 13.003 only muddies the waters by clarifying that, while "[a]gencies shall use simplified acquisition procedures to the maximum extent practicable for all purchases of supplies or services not exceeding the simplified acquisition threshold," that policy "does not apply if an agency can meet its requirement using...[e]xisting indefinite delivery/indefinite quantity contracts.” 


\section{Single Awards Dominate Despite Regulatory Preference}

All of which makes it all the more strange — in this day and age - that, once you find the relevant guidance on how IDIQs actually work, FAR 16.500 leads by pointing out that "[t]his subpart...establishes a preference for making multiple awards of indefinite-quantity contracts." (Emphasis added.) FAR 16.504(c) then elaborates on the multiple award preference at length.

At which point the GAO's recent report reminds us that policy and guidance, without teeth, are meaningless. The GAO notes that, despite FAR 16.500(a)'s established preference for multiple awards, "[o]f the DOD awards for the indefinite-delivery /indefinite-quantity (IDIQ) contract type during this period, about three-quarters were made to a single contractor, rather than multiple contractors." (That implies only a slight increase from approximately 70\% from the prior GAO report.) Elsewhere in the report, the GAO indicated that "DOD obligated about two-thirds of its IDIQ contract obligations on single-award IDIQ contracts." (That implies only a slight increase from approximately $60 \%$ from the prior GAO report.)

Either way, our sense is that, the reality that single awards comprise an amount between two-thirds (of the dollars projected to flow through IDIQs) and three-quarters (of the IDIQ contracts) does not seem to reflect a "preference for multiple awards," and the trend line is towards less competition in IDIQs. Indeed, Table 1 in the report, below, suggests that the GAO understated the single-award trend; the Table's numbers of transactions indicated that single award IDIQs represented 79\% of all DOD IDIQs in 2015, 78\% in 2016, and a whopping 85\% in 2017. (For FY 2017, that's 6,242 single-award indefinite-delivery contracts (that were competed), 2,069 single-award indefinite-delivery contracts (that were not competed), and only 1,423 multiple-award indefinite-delivery contracts.)

Table 1: Number of Indefinite-Delivery Contracts Entered into by the Department of Defense, Fiscal Years 2015 through 2017

\begin{tabular}{|l|c|c|c|}
\hline & $\mathbf{2 0 1 5}$ & $\mathbf{2 0 1 6}$ & $\mathbf{2 0 1 7}$ \\
\hline $\begin{array}{l}\text { Single-award indefinite-delivery contracts } \\
\text { (competed) }\end{array}$ & 5603 & 4985 & 6262 \\
\hline $\begin{array}{l}\text { Single-award indefinite-delivery contracts } \\
\text { (not competed) }\end{array}$ & 1999 & 2074 & 2069 \\
\hline $\begin{array}{l}\text { Multiple-award indefinite-delivery contracts } \\
\text { (all competed) }\end{array}$ & 1984 & 1948 & 1423 \\
\hline Total indefinite-delivery contracts & $\mathbf{9 5 8 6}$ & $\mathbf{9 0 0 7}$ & $\mathbf{9 7 5 4}$ \\
\hline
\end{tabular}

Source: GAO analysis of Federal Procurement Data System - Next Generation data. | GAO-18-412R

Nor should we expect that trend to reverse anytime soon. In a compelling recent example, in one of its highest profile pending solicitations, the DOD reminds us that the multiple award preference, in practice, is the exception, not the rule. On July 18, Under Secretary of Defense for Acquisition and Sustainment (A\&S) Ellen Lord signed a D\&F providing authority to award to a single source the DOD's JEDI Cloud task order contract with a $\$ 10$ billion maximum dollar value. See Solicitation Number: HQ003418R0077_JEDI_CLOUD_RFP on https://www.fbo.gov/. Oracle promptly protested to the GAO, asserting, among other things, that:

DoD's single awardee IDIQ contract approach is contrary to statutory and regulatory requirements; contrary to the perspective of numerous industry experts that a multi-vendor IDIQ contract offers the most advantageous approach for DoD's near term and long term technology requirements; contrary to the market trend toward multi-cloud environments; and contrary to DoD's own stated objectives of flexibility, innovation, a broad industrial base, and keeping pace with evolving technology. 
Also available on https://www.fbo.gov/. Lord's D\&F appears entirely consistent with her stated emphasis on speed, rather than bureaucracy, control, or regulation. See, e.g., Memorandum from Under Sec'y of Defense (A\&S), Middle Tier of Acquisition (Rapid Prototyping/Rapid Fielding) Interim Authority and Guidance (Apr. 16, 2018), http://acqnotes.com/wp-content/uploads/ 2018/05/OSD-Middle-Tier-of-Acquisition-Interim-Authority-and-Guidance-16-Apr-2018..pdf (authorizing "a new pathway, distinct from the traditional acquisition system"); Ellen M. Lord, Current State of Defense Acquisition and Associated Reforms, Testimony Before the S. Comm. on Armed Services (Dec. 7, 2017), https://www.armed-services.senate.gov/imo/media/doc/Lo rd_12-07-17.pdf (planning to reduce, by 50\%, the typical lead time from requirement until awarding a major weapon systems contract; leveraging nontraditional contracting tools, including "other transactions").

As has become practice, the DOD is merely following the rules in papering over avoidance of the stated multiple-award policy. By way of explanation, the GAO elaborates, in footnote 1:

With limited exceptions, the FAR requires contracting officers, to the maximum extent practicable, to give preference to making multiple awards of IDIQ contracts... However, the FAR also establishes that there are times where contacting officers must not use the multiple award approach-including when it is not in the best interest of the government.

The GAO's data suggests that procuring agencies have concluded — and behaved consistent with their belief that-the stated preference for a multiple award approach is not in the best interest of the Government. The GAO explained that, while many of the solicitations that led to these contracts "contemplated competition among the contract holders for subsequent orders" extraneous considerations ultimately derailed any such competition. The bottom line remains: "nearly all of the contracts [that the GAO] reviewed contained provisions that, while not explicitly limiting competition, may have the potential, under certain circumstances, to reduce the number of contractors...eligible to compete for the orders. Generally, these provisions were in service of some other goal, such as increasing federal contracting opportunities for small businesses by setting aside certain task or delivery order competitions among these firms." (Emphasis added.)

This reminds us of former Office of Federal Procurement Policy administrator Steve Kelman's failed "Mayflower Compact" effort. As Steve explains, we saw this coming.

[I]n early 1997, as I was nearing the end of my tenure [at OFPP, I became]... concerned that government contractors, in pursuit of advantage over competitors, might allow customers to ignore the simple rules established for streamlined competition for orders and accept business from those [prefer]ing sole-source buys.... I repeatedly urged GWAC/[General Services Administration] managers to establish a Mayflower Compact. The name alluded to the agreement the Pilgrims had set up among themselves to enforce laws in their new, governmentless land.

My idea was that this world of new vehicles was like the new world to which the colonists had come, and managers of these vehicles needed to agree among themselves to enforce constraints that established the context in which they competed against one another. However, with GWACs/GSA flush with revenues, the Mayflower Compact was never broadly adopted.

Kelman, The Mayflower Revisited, FCW (June 14, 2004), https://fcw.com/articles/2004/06/14/kelman-the-mayflower-revisited. aspx. It didn't work then, and it's not working now. Instead, IDIQ vehicles became "hunting licenses." See Competition for Task Orders: The Exception or the Rule?, 18 N\&CR II 42; Postscript: Multiple Award Schedules, 12 N\&CR II 3. See also Palmer, The Cost of Convenience, Government Executive (Mar. 1, 2006), https://www.govexec.com/magazine/features/2006/ 03/the-cost-of-convenience/21281/. And both Government buyers and private sector sellers repeatedly demonstrate that they prefer single vendors to the competition (either meaningful or formalistic) inherent in multiple awards.

\section{What To Make Of All This}

The GAO's report is admittedly descriptive and, indeed, the GAO concedes that it was making no recommendations in its report. That's a shame. We can think of two recommendations that follow logically from the GAO's research. 
First, to the extent that IDIQ contracting is here to stay and represents such a significant percentage of the current procurement landscape, Congress, the OFPP, the FAR Council, the Section 809 Panel, or all of the above, would be well served to put some thought into reorganizing or redesigning the FAR — which, as stated in FAR 1.101, was "established for the codification and publication of uniform policies and procedures for acquisition by all executive agencies"- to better reflect modern practice. (Of course, this is but one example of a topic with which the FAR has failed to keep pace. FAR Part 37, "Service Contracting," is every bit as antiquated and unhelpful, offering little helpful guidance, but maintaining the (now dead letter) prohibition on personal services contracts, FAR 37.104 (see, e.g., Swan, Dead Letter Prohibitions and Policy Failures: Applying Government Ethics Standards to Personal Services Contractors, 80 Geo. Wash. L. Rev. 668 (2012) (arguing "that the personal services prohibition represents an outdated and inefficient method for protecting the government's interest and should be abolished") and little known rules at FAR 37.116, intended to facilitate circulation of the $\$ 1$ coin, which remains one of the most bizarre (albeit not terribly burdensome) nuggets buried in the FAR.

Second, Congress or the FAR Council could raise the bar and mandate more meaningful impediments to single-award IDIQs, whether in 10 USCA $\S 2304 a(d)(4)$ and 41 USCA $\S 4103(d)(4)$, FAR Part 16, or elsewhere. The statutory mandate today offers little more than a highly discretionary delegation to the FAR Council that "the regulations...establish a preference for awarding, to the maximum extent practicable, multiple task or delivery order contracts...[and] establish criteria for determining when award of multiple task or delivery order contracts would not be in the best interest of the Federal Government." And decades of experience demonstrate that general encouragement—even supplemented by memoranda (or D\&F) drafting exercises—are not going to change the marketplace's behavior. Moreover, the GAO's data suggest that doing so would be far more disruptive than previously assumed, and we have no reason to think that the DOD or other agencies are sufficiently staffed to manage more IDIQ contractors. Nor does it seem that Congress is particularly exercised about these trends, with legislative attention largely drawn to task and delivery order bid protest rights (and thresholds).

Instead, maybe it's time to jettison the stated preference for multiple awards. If $85 \%$ of the DOD's IDIQs in FY 2017 were single awards, the policy favoring multiple awards is teetering on the verge of dead letter. What's worse, the GAO's data suggest that the primary result of the FAR's multiple-award preference is subjecting CO's to the seemingly pointless exercise of generating D\&Fs. We think that the DOD's 1102s had better things to do with their time in FY 2017 than generate 8,300 D\&Fs, and the time they did spend was "time that [wa]s not devoted to the central function and goal of acquisition," as noted in Petty Rules: The Friction in the System, 31 NCRNL II 68 (although Vern's example there is not a perfect analogy). Nor do we think that churning out this type of formalistic paperwork enhances job satisfaction. Human behavior suggests that widely ignored mandates and polices breed cynicism, and that cynicism bleeds over to other (arguably more important) mandates. Maybe this aspiration-however well intentioned-has outlived its usefulness. SLS 